\title{
Concepcións e prácticas do coidado para a mitigación da contaminación do río Ocoa por parte dos habitantes do barrio Ciudad Porfía da cidade de
} Villavicencio

\section{Conceptions and Practices of Care for Mitigation of Pollution of the Ocoa River by the Inhabitants of the Ciudad Porfía Neighborhood of the Villavicencio City}

Luz Maritza Benítez Oviedo (iD) Universidade de Manizales (Colombia).

\begin{abstract}
Resumo
Este artigo ten o propósito de presentar as concepcións e prácticas do cuidado da comunidade da cuenca hidrográfica do río Ocoa, sector barrio Ciudad Porfía na cidade de Villavicencio, co fin de identificar as causas e as boas prácticas do coidado para a mitigación da contaminación do rio, promovendo entre os habitantes da zona o coidado do medio ambiente, xestionando a cultura e a conciencia ambiental. En especial coa poboación infantil e do adulto maior, como sementeiros de desenvolvemento e xestión do cambio, promoveuse desde o colectivo o liderado ambiental e o coidado do recurso auga. O obxectivo xeral é identificar as concepcións e prácticas do coidado para a mitigación da contaminación do afluente, por parte dos habitantes do barrio Ciudad Porfía. A investigación busca comprender as concepcións e prácticas de coidado da marxen dereita do río Ocoa, por parte dos habitantes do barrio e o resultado é a consolidación da formulación de estratexias para mitigar a súa contaminación.
\end{abstract}

\section{Astract}

This article has the purpose of presenting the conceptions and practices of the care of the community of the Ocoa river basin, Ciudad Porfia neighborhood sector in the city of Villavicencio, in order to identify the causes and good practices of care for the mitigation of the contamination of the Ocoa river, promoting the care of the environment among the inhabitants of the area; managing culture and environmental awareness. In particular, with the children and the elderly population, as seedlings of development and change management, promoted from the collective environmental leadership and the care of the water resource. The general objective is to identify the conceptions and practices of care for the mitigation of pollution of the Ocoa river, by the inhabitants of the Ciudad Porfía. The research seeks to understand the conceptions and practices of care of the right bank of the Ocoa river, by the inhabitants of neighborhood and the result it is the consolidation of the formulation of strategies to mitigate the contamination.

\section{Palabras chave}

Medio ambiente; coidado; conciencia ambiental; auga; educación.

\section{Key-words}

Environment; care; environmental awareness; water; education. 


\section{Introdución}

A presente investigación "Concepcións e prácticas do coidado para a mitigación da contaminación do río Ocoa por parte dos habitantes do barrio Ciudad Porfía da cidade de Villavicencio" xorde ao observar a vulnerabilidade da zona dos habitantes que conviven na zona da marxe dereita do río Ocoa sector Barrio Ciudad Porfía na cidade de Villavicencio, por canto existe deterioro do ambiente físico, biótico e social. Considérase determinante para a comunidade recoñecer as concepcións e prácticas que desempeñan con relación á cuenca hidrográfica. Enténdese por malas prácticas, todas aquelas accións que deterioran e destrúen os recursos naturais da zona, por exemplo o publicado pola Revista da Unillanos, volume 21 , do ano 2012, onde se indica que a ocupación da praia do río coa construción de vivendas ou asentamentos, botar residuos ao río, a tala de árbores, o verquido de augas residuales á fonte hídrica, entre outros. Crendo como un aporte importante xerar un estado das concepcións e prácticas da comunidade para lograr recoñecer estratexias para mitigar a contaminación do río Ocoa por parte dos habitantes do barrio Ciudad Porfía.

En particular, a rexión oriental en Colombia caracterízase por estar experimentando problemáticas ambientais, en especial, con relación ás cuencas hidrográficas, situación que se evidencia a primeira ollada polos seus habitantes. Con todo, parece que a poboación aínda non estima as consecuencias e severidade destas. No correspondente á cidade de Villavicencio, co cambio demográfico nos últimos anos, a cidade tivo unha gran transformación en canto ao número de habitantes e a paisaxe natural; isto xerou novos asentamentos e altos índices de contaminación ambiental. Segundo datos da Alcaldía de Villavicencio (2012), a cuenca hidrográfica do río Ocoa, conta cun área total de 282.9 km².

A área de estudo se focaliza no Barrio Ciudad Porfía, que está situado na comuna número oito (8) en Villavicencio. Como o indica o xornal El Tiempo: "o pasado 18 de agosto de 2016, segundo publicacións polos diferentes medios de comunicación locais, na carreira 51, do sector por un desbordamiento do rio, 12 familias aledañas perderon o lugar de residencia". A condición de vulnerabilidade da poboación da zona, podería dar a pensar que estas situacións non son percibidas pola comunidade como un risco inmediato, senón até que ocorre un evento grave que limite o asentamento na zona. En síntese, requírese de xeito inmediato establecer accións que permitan mellorar a percepción do coidado do medio ambiente, en especial da fonte hídrica do río Ocoa, así como, xerar liderado entre a poboación para mitigar o deterioro ambiental. 
As situacións mencionadas son de gran interese de investigación e levaron a indagar máis aló do concepto literario de educación ambiental e convertíronse no aliciente para indagar sobre os alcances que se poden obter a través das organizacións non gobernamentais, os colectivos e as organizacións comunitarias

Inicialmente ao consultar o tema non se atopa moito material escrito sobre o sector da comunidade, máis aló de que se recoñece inicialmente os cintos de pobreza por mor de ser unha comunidade que se levantou de forma ilegal, mediante invasión e un centro receptor de desprazados nos anos 90, na época na cal Colombia e o Departamento de Meta, sostivo as maiores cifras de desprazamento. Polo tipo de cuestionamentos e experiencia obtida limitouse á comunidade da investigación ${ }^{1}$.

Realizouse unha extensa revisión de artigos sobre educación ambiental e algunhas análises gobernamentais en normatividade, cifras ou estatísticas realizados por organismos nacionais. Pero non se evidenciaron estudos vinculados necesariamente coa comunidade da investigación. Con todo, esta revisión de antecedentes serve para nutrir esta parte e os aspectos teóricos, en tanto son investigacións asociadas.

1 Seleccionouse como "comunidade de investigación" a poboación da riveira do marxe dereito do río Ocoa, sector barrio Ciudad Porfía.
Para o marco teórico preténdese expoñer o resultado de conceptos académicos e sociais, utilizando importantes fontes como son, por exemplo, Amartya SEN (Desenvolvemento e liberdade), Leonardo BOFF (O coidado esencial e O coidado necesario), PNUD (Soster o progreso humano: reducir as vulnerabilidades e construír resiliencia e Obxectivos do Desenvolvemento Sostenible Axenda 2030).

O deseño da metodoloxía levouse a cabo baixo un proceso de procura que conduciu a realizar revisión bibliográfica que permitise identificar a metodoloxía máis apropiada a criterio da investigadora e seleccionar o tipo de investigación mixto, cuali-cuantitativo descriptivocomprensivo.

Para acadar os propósitos da investigación, foi necesario realizar 87 enquisas á comunidade, aproveitando o aporte de fontes orais para establecer o concepto que se ten desde a comunidade e tómase como punto de partida establecer un plan de acción ou as recomendacións que permitan iniciar coa concientización a un grupo da comunidade sobre as boas prácticas do coidado para a mitigación da contaminación do río Ocoa por parte dos habitantes da rivera dereita do barrio Ciudad Porfía.

Como investigadora expreso o meu agradecemento a todas as persoas que 
colaboraron neste proceso, principalmente á comunidade e a Fundación Caepa por permitirme ser parte do voluntariado desta institución, como profesional, polo seu apoio ao deixarme desenvolver as actividades deste estudo nas súas instalacións, para acadar o obxectivo da investigación: lograr interpretar as concepcións e prácticas do coidado para a mitigación da contaminación do rio Ocoa, por parte dos habitantes do barrio Ciudad Porfía da cidade de Villavicencio.

\section{Marco teórico}

\section{O desenvolvemento social e humano como ampliación de capacidades}

\begin{abstract}
A Axenda 2030 e os Obxectivos para o Desenvolvemento Sostible, formulada no mes de setembro do ano 2015, sinalan dezasete (17) obxectivos do desenvolvemento sostible, os cales suscitan un cambio de paradigma e de pensamento global. Igualmente, representa os desafíos necesarios para a humanidade, retos imperantes para alcadar a sostenibilidade do planeta e garantir igualdades para todos os seres humanos. O desafío para a humanidade é xigante: para o ano 2030 debe garantir e implementar estes obxectivos; de non ser así, a humanidade e a vida como se coñece actualmente, está en risco.
\end{abstract}

O Obxectivo 3 sinala como medida de adopción: garantir unha vida sa e promover o benestar de todos en todas as idades. Este é o chamado ás comunidades, desde os territorios, que son convocados a coordinar e liderar os procesos que poidan permitir mellorar as condicións de vida.

Con respecto ao Obxectivo 4, educación de calidade, é importante comprender que o ser humano é o resultado de toda a súa contorna, a súa cultura, a construción familiar e a comunitaria.

Para LEÓN, en Educere (2007: 596), a educación é un proceso humano e cultural complexo. Para establecer o seu propósito e a súa definición é necesario considerar a condición e natureza do home e da cultura no seu conxunto, na súa totalidade, para o que cada particularidade ten sentido pola súa vinculación e interdependencia coas demais e co conxunto.

Grazas á educación o ser humano forma a súa mente, crea unha forma de razoar, a cal pode transformar constantemente. De tal forma o pensamento créase, reconstrúese, evalúase e evoluciona; sendo esta a principal diferenza con outras especies, quizais por isto o ser humano logrou sobrepoñerse ante outras especies.

Doutra parte, desde o Obxectivo 6, de desenvolvemento sostible, o obxecto é garantir a disponibilidade da auga, a súa xestión sostible e o saneamiento. 
Unha comunidade sen o recurso auga, literalmente está exposta a crise e a problemas de salubridade, e sometida a situacións de estrés. A xestión integral deste recurso, está exposta a outras condicións en especial á xestión de recursos que permitan equidade para as comunidades.

Como indica COLBY e SALYBA (1984: 177), as máis recentes avaliacións dos especialistas e organizacións internacionais conectadas cos problemas da auga suxiren que para o ano 2025, máis das dúas terceiras partes da humanidade sufrirá algún estrés por falta deste líquido. No caso de Colombia, no Departamento do Meta, segundo a análise e perspectivas das coberturas de acueducto e alcantarillado (CASTRO, RUBIO e RODRÍGUEZ 2013: 1), o $43 \%$ dos municipios presentan unha calidade da auga para o consumo humano con nivel de risco inviable. É dicir, non contan cun sistema de acueducto e alcantarillado que garantan a calidade da auga, o que conclúe en problemas sanitarios.

\section{O coidado: unha noción expansiva do ser, ao nós e a Nai Terra}

A Nai Terra ou Pachamama como a aclaman na lingua quechua, como boa nai, proporciona todo o necesario para que os seres humanos poidan ter alimento, abrigo, teito, interactuar con outras especies e un gran número de recursos naturais, como son: o aire, a auga, o chan, a fauna e a flora. Con todo, como o indico GANDHI: "a terra é suficiente para todos, pero non para a voracidad dos consumidores", e é que o que a inicios de nosa era, quizais parecese algo ousado pensalo, na realidade actual o ser humano, tras séculos de historia, se superpuso fronte ás outras especies, desenvolveu históricamente habilidades que lle permitiron dominar o planeta, domesticar algunhas especies, dominar outras, comprender o ciclo que teñen os recursos naturais. No entanto, isto non foi suficiente, o Banco Mundial estimou que para o ano 2017 a poboación mundial acadou os 7.53 mil millóns de habitantes, a explosión demográfica supero calquera proxección e con este aumento o uso indiscriminado dos recursos naturais. A nosa nai Terra sangra e o fai a través das súas venas: nos seus mares e ríos circula contaminación, metais pesados, plásticos, ademais, se caza indiscriminadamente. Este é entón o momento histórico para adquirir conciencia como o indicou BOFF (2013: 2). A conciencia que vai cobrando cada vez maior difusión no mundo, aínda cando non en grao suficiente, suscítase do seguinte modo: si levamos adiante este xeito noso de ser e deixamos vía libre á lóxica da nosa máquina produtivista, poderemos chegar a efectos irreversibles para a natureza e para a vida humana. 


\section{Educación ambiental:}

\section{estratexia para o coidado do medio ambiente}

Para SUREDA e COLOM (1989:90), pódese afirmar que a educación ambiental é consecuencia do cambio de lectura que o home empeza a realizar, a fins da década dos sesenta, do escenario da súa vida. Desde ese entón a humanidade comeza a comprender os efectos que trae consigo o avance industrial e o inicio o desenvolvemento tecnolóxico. Doutro lado, FRAUME (2007: 9) cita á educación ambiental como a acción e efecto de formar e informar a colectividades sobre todo o relacionado coa definición, conservación e restauración dos distintos elementos que compoñen o medio ambiente. Conferindo á educación ambiental, a gran responsabilidade de instruír para a sostenibilidade dos territorios. Quizais, por isto NOVO (2009:96), considéraa como "unha xenuina educación para o desenvolvemento sostenible". Así como "algo pode contribuír a educación a contrarrestar os efectos negativos da globalización económica é fomentando en nenos, novos e adultos un cambio de mirada" (NOVO, 2009:97).

\section{O coidado da auga, o noso} recurso común

Desde o contexto nacional, é moi fácil atopar na maioría de lugares varias fontes de auga. Segundo o Informe Nacional sobre a xestión da auga en Colombia (2000:7), debido a súa ubicación xeográfica e ás súas condicións de relevo, Colombia ten unha precipitación media anual de $3.000 \mathrm{~mm}$, que representa unha riqueza importante de recursos hídricos, cando é comparada co promedio mundial de precipitación anual, equivalente a 900 $\mathrm{mm}$ e co promedio anual de Suramérica, da orde dos $1.600 \mathrm{~mm}$. En termos de caudal específico de escorrentía superficial, Colombia presenta un caudal de $58 \mathrm{l} / \mathrm{s} / \mathrm{km}^{2}$, tres veces maior que o promedio sudamericano $\left(21 \mathrm{l} / \mathrm{s} / \mathrm{km}^{2}\right)$ e seis veces maior que a oferta hídrica específica promedio a nivel mundial $\left(10 \mathrm{l} / \mathrm{s} / \mathrm{km}^{2}\right)$. É dicir que en condicións naturais o país ten unha maior oferta de auga doce con respecto ao promedio mundial, o que pode ser unha grande oportunidade para proxectar e acadar o crecemento sostible da nación, do territorio e dos cidadáns que a conforman.

Os territorios normalmente limítanse ao redor das fontes hídricas. Como indica DOUROJENNI na Xestión da auga e as cuencas en América Látina, con relación á cuenca hidrográfica.

"É un territorio que é delimitado pola propia natureza, esencialmente polos límites das zonas de escurrimiento das augas superficiais que convergen cara a un mesmo canle. A cuenca, os seus recursos naturais e os seus habitantes posúen condicións físicas, biolóxicas, eco- 
nómicas, sociais e culturais que lles confiren características peculiares. Físicamente, representa unha fonte natural de captación e concentración de auga superficial e subterránea e, polo tanto, ten unha connotación esencialmente volumétrica e hidrológica. Ao mesmo tempo, tanto a cuenca como, sobre todo, a auga captada por ela é unha fonte de vida para o home. Pero tamén é orixe de risco cando ocorren fenómenos naturais extremos ou se producen alteracións por contaminación" (DOUROJENNI ,1994: 2).

Actualmente, o planeta afronta serios problemas ambientais, que causan grande preocupación sobre a sostenibilidade ${ }^{2}$ e o futuro da terra. As cuencas hidrográficas conforman partes dos recursos naturais que se van deteriorando aceleradamente; isto atópase asociado tamén, a que algúns territorios son máis vulnerables polas condicións sociais e culturais dos seus habitantes. Ademais as cuencas hidrográficas ostentan condicións biolóxicas, físicas e económicas, as cales outórganlle ambientes e características particulares. Os territorios das cuencas proporcionan unha maior relación entre

2 Sostenibilidade: Proceso de racionalización das condicións sociais, económicas, educativas, xurídicas, éticas, morais e ecolóxicas fundamentais que posibiliten a adecuación do incremento das riquezas en beneficios da sociedade sen afectar ao medio ambiente, para garantir o benestar das xeracións futuras. Tamén pode denominarse sustentabilidade (FRAUME. 2007: 14) os habitantes, as pontes, as vías de acceso, os perigos en común, así como a oportunidade de construír en colectivo estratexias que mitiguen os riscos aos que se expoñen e con isto diminúanse os riscos ou as dificultades máis frecuentes. Algunhas das situacións de risco máis frecuentes, son a contaminación da auga por mor das augas residuais domesticas ${ }^{3}$ ou augas residuais industriais ${ }^{4}$, así como as inundacións por mor da invasión das praias dos ríos.

A auga é un recurso común que está sendo deteriorado nas comunidades. A humanidade enfróntase quizais a un dos máis grandes desafíos dos últimos tempos, a auga é un dos elementos máis útiles que nos proporciona a terra, sendo entón necesario para todos recuperar e incorporar valores que permitan regular efectivamente o seu uso, coidala para evitar que nesta incorpórense outros elementos e vixiala para prever posibles

$3 \quad$ Augas residuais domésticas: So unha franxa ubicada entre o $5 \%$ e o $10 \%$ das cabeceiras municipais de Colombia, efectúa algún tipo de tratamento de augas residuais. Esta situación constitúese nunha das principais fontes de alteración da calidade da oferta hídrica superficial. A inadecuada disposición de residuos sólidos en verquedeiros a ceo aberto na maioría dos municipios colombianos, xera lixiviados que afectan aos acuíferos (CEPAL 2000:82).

4 Augas residuais industriais: A calidade dos recursos hídricos sufriu un deterioro acelerado nos últimos tempos e a contaminación de orixe industrial é un dos principais factores que contribúen a súa degradación, co consiguinte descenso da calidade de vida dos colombianos (CEPAL, 2000:82). 
cambios da canle natural e evitar riscos de inundacións das comunidades. En resumo, todo o ciclo hidrolóxico debe ser monitoreado, controlado para diminuír o despilfarro e a contaminación. Sendo necesario incorporar nas comunidades unha mensaxe de resiliencia social ${ }^{5}$.

$\mathrm{Na}$ actualidade obsérvase que $\mathrm{o}$ río Ocoa na cidade de Villavicencio, como fonte natural de auga doce, perdeu a súa capacidade hídrica, isto tendo en conta varios factores como son: asentamientos humanos ilegais arredores á cuenca do río, vertimientos domésticos e de labores comerciais, disposición de residuos sólidos. Na sumatoria destes factores, se denota a falta de conciencia social e comunitaria sobre a prevalencia do coidado do recurso hídrico, fauna e flora. Sen descoñecer que desde o principio - Estado foi incapaz de recoñecer e aplicar a normativa legal con respecto á protección de cuencas hidrográficas e ao principio fundamental que é o interese xeral. Neste caso o coidado e a protección dos recursos naturais, debe primar sobre os intereses particulares dos axentes que fixeron parte dos elementos contaminantes desta importante cuenca para a cidade de Villavicencio. Segundo

\footnotetext{
5 Resiliencia Social: Capacidade dun sistema social ou ecolóxico de absorber perturbacións e manter ao mesmo tempo a mesma estrutura básica e xeito de funcionar, asociado tamén á capacidade de auto organización e de adaptarse ás tensións e os cambios. (REDALYC, 2011: 35).
}

un estudo realizado por DISHINTONG (2015:8), mediante a aplicación manual de métodos analíticos para a avaliación da calidade fisicoquímica da auga, mediante un muestreo, atópase na zona suspensión de sólidos totais, fósforo, nitritos, nitratos, $\mathrm{DQO}, \mathrm{DBO}_{5}$, a demanda química de osíxeno e a demanda bioquímica de osíxeno; en gran parte isto é un tema moi importante para a comunidade dado que a calidade do auga deteriorouse no sector. $\mathrm{Na}$ actualidade é probable que o resultado "significativo" dese estudo estea alcanzando o nivel "grave" dado que se evidencia na comunidade o aumento do nivel de contaminación odorifera e un deterioro da paisaxe natural.

Un antecedente investigativo de ARROYABE, BUILES e RODRÍGUEZ (2012:40), este texto é unha reflexión da forma como o home relacionouse coa súa contorna, e como iso, xerou dificultades na xestión ambiental, e fai énfasis na planificación e manexo do recurso hídrico, pasando por un reconto xeneral dos avances normativos asociados ao auga, que impactaron a súa xestión. Para rematar, suscítase unha discusión en busca dun cambio de paradigma e de cultura social e ambiental a favor dunha mellor xestión socio ambiental do recurso hídrico que propenda pola sostenibilidad do auga a diferentes escalas. Para considerar o desenvolvemento sostible, débese iniciar con revisar os problemas ambientais das nosas comunidades. Sendo a primeira 
ollada evidente o aumento destes en complexidade, na actualidade o noso país vive frecuentemente inundacións, contaminación da auga, derrames de contaminantes, contaminación auditiva, contaminación do aire, entre outros. Devanditos temas requiren a revisión especializada de expertos e a creación de grupos intersectoriais que permitan plantexar e xerar solucións pertinentes que permitan mitigar os efectos da contaminación.

As perspectivas anteriores poden aportar tamén á mitigación da contaminación a través da educación ambiental e aadopción de novas medidas que contribúan con diminuír o nivel de contaminación grave do auga do río Ocoa, sector barrio Ciudad Porfía.

Dito así, no presente artigo preséntanse os resultados da pregunta que se tivo na investigación: cales son as concepcións e prácticas do coidado para a mitigación da contaminación da marxe dereita do río Ocoa, por parte dos habitantes do barrio Ciudad Porfía na cidade de Villavicencio?

\section{Metodoloxía}

A investigación é unha investigación con enfoque mixto cuali-cuantitativo descriptivo comprensivo que, a partir da análise de testemuños de suxeitos activos na comunidade, busca comprender as concepcións e prácticas do coidado para a mitigación da contaminación da marxe dereita do río Ocoa, por parte dos habitantes do barrio Ciudad Porfía da cidade de Villavicencio.

Respecto da investigación cualitativa ocúpase da vida das persoas, de historias, de comportamentos, ademais do funcionamento organizativo dos movementos sociais segundo Strauss e CORBIN (1990:17). A investigación cualitativa é para Denzin LINCOLN (1994:2), multimetódica, naturalista e interpretativa. Por outra banda, MANSON (2006:216), recoñece que a particular solidez da investigación cualitativa xace no coñecemento que proporciona achegas da dinámica dos procesos sociais, do cambio e do contexto social e na súa habilidade para contestar, neses dominios, ás preguntas como? por que?. Con todo, os distintos enfoques cualitativos teñen as súas propias regras e os seus propios procedementos analíticos e explicativos. A investigación cualitativa asúmese desde a hermenéutica para lograr analizar o contexto natural da comunidade da investigación.

A investigación científica describe características dun conxunto de suxeitos ou áreas de interese. Como indica TAMAYO (1998:66). Para o caso desta investigación centrámosnosna comunidade aledaña á marxe do río Ocoa, comunidade barrio 
Ciudad Porfía. Este xeito de investigar é considerada como unha forma de pensar máis que como colección de estratexias técnicas. Para categorizar a información da investigación atendemos ao descrito por BONILLA e RODRÍGUEZ (1997:173). Inicialmente recoñecéronse os elementos ou calidades recurrentes entre un conxunto de información, neste caso a información que se recompila na comunidade do estudo. Posterior, débese xerar subconxuntos de información relacionados con características e propiedades específicas; para esta investigación revisaranse cos resultados da información tipo enquisa. Seguidamente procederase a definir os conceptos que se denominen o máis fiel á cada categoría previamente definida, para xerar as propostas para a comunidade, partindo do resultado do proceso de categorización. Isto tamén grazas ao uso da investigación cuantitativa segundo VASILACHIS (2009:30), o proceso de análise dos datos, ao que non se considera neutral, e que debe ser exposto en cada un dos seus pasos a fin que outros investigadores poidan chegar a iguais resultados reiterando o mesmo procedemento analítico para acadar as recomendaciones finais da investigación.

No que confire á investigación cuantitativa, como o indica TAMAYO: "As técnicas utilizadas na investigación cuantitativa son a observación, a enquisa e a entrevista. $A$ observación é a procura deliberada, levada con coidado e premeditación, en contraste coas percepcións causales, e en gran parte pasivas, da vida cotiá" (1999:15). Deste xeito aplicouse na comunidade a investigación.

Como indica BONILLA e RODRíGUEZ: "o dilema entre os métodos cuantitativo e cualitativo pode reducirse [...] á preocupación por establecer cal dos métodos é mellor en si mesmo. Con todo, en termos científicos, o dilema debería reformularse para indagar como pode lograrse unha mellor comprensión da realidade social" (2000:61).

En resumo, co primeiro obxectivo da investigación -a caracterización socioambiental da poboación aledaña ao barrio Ciudad Porfía- dáse resposta coa investigación cualitativa. Seguidamente en atención ao segundo obxectivo interpretar as concepcións do coidado do medio ambiente por parte dos habitantes do barrio Ciudad Porfía da cidade de Villavicencio- dáse resposta á parte da investigación cualitativa. Así mesmo, co fin de acompañar a investigación desde a parte comprensiva inclúense testemuños e algunhas imaxes das vivencias.

Poboación: Sector aledaño á marxe dereita río Ocoa do barrio Ciudad Porfía, habitantes de condición socioeconómica vulnerable, segundo o Instituto Agustín Codazzi e o DANE 6 , estrato uno (1). Barrio

6 DANE: Departamento Administrativo Nacional de Estadística (2012). 
situado na Cidade de Villavicencio no Departamento do Meta (Colombia). Zona que nos últimos anos foi ameazada por inundacións, cheiros desagradables, disminución da canle do río e aumento de residuos na zona de praia do río. Para desenvolver a investigación e determinar o número da mostra esta suscitásese a través da fórmula de muestreo aleatorio simple. Inicialmente proxectouse o tamaño da mostra utilizando a fórmula de muestreo aleatorio simple.

Mostra: o tamaño da mostra determinouse usando a fórmula de aleteo simple sendo 87 o número establecido para a enquisa na investigación, determinando que se preguntaría a un membro por familia nunha marxe de distancia de cada 15 casas, buscando que fose unha persoa do núcleo familiar maior de idade, isto co fin de garantir maior confianza na información recibida. Preferiblemente realizarase os fins de semana, sábados e domingos, para ser máis fácil acceder á comunidade. Mediante muestreo aleatorio, obteranse as estatísticas e os resultados das preguntas na enquisa.

\section{Técnicas e instrumentos de recolección} de información: enquisa, a cal aplicouse a individuos da comunidade, co obxectivo de coñecer as condutas e as futuras intencións de actuación. Anéxase o instrumento. Segundo ALVIRA (1999:34), a enquisa é esencialmente unha técnica de recolleita de información que a convirte nun método que admite diferentes deseños de investigación.

Neste caso, a través da enquisa espérase interpretar as concepcións sobre o coidado do medio ambiente.

Fase 1. Requisitos: Formulación da Investigación. Definir obxectivos, comunidade, metodoloxía e instrumentos.

Fase 2. Inicio: Aprobación e proba dos instrumentos para o inicio da recolección de insumos a través das técnicas ou instrumentos.

Fase 3. Desenvolvemento: A través da enquisa, medir e interpretar os resultados que permitan facilitar a análise destes para lograr realizar a formulación de estratexias de apoio á comunidade, mellorar a interpretación cuantitativa e permitir xerar o informe final e as recomendacións.

\section{Resultados}

Na aplicación do instrumento da enquisa, desenvolvéronse 17 preguntas ou interrogantes, as cales foron deseñadas para dar resposta ás variables obxecto da investigación, a continuación as que permiten observar as variables cualitativas e de comprensión, co primeiro obxectivo caracterización socio-ambiental da comunidade: 


\section{Nivel educativo máximo acadado}

O 48\% da poboación encuestada cursó estudos de primaria. Mentras apenas 2 persoas da poboación encuestada alcadaron a educación superior (Figura e Táboa 1).

Percepción da capacidade e cobertura na calidade dos servicios públicos mínimos. A comunidade creou o acueducto e o alcantarillado a partir do ano 1990 sendo entón un esforzo colectivo comunitario. En promedio, o $66 \%$ da comunidade ten vinculación con este sistema de transporte da auga. Con todo, o restante $34 \%$ ten nas súas vivendas os coñecidos pozos ou perforacións na terra das cales extraen auga. Basicamente a comunidade encuestada indica que o sistema de acueducto non ten capacidade para cubrir as vivendas que se atopan na parte inferior aledaña ao río (Táboa 2).

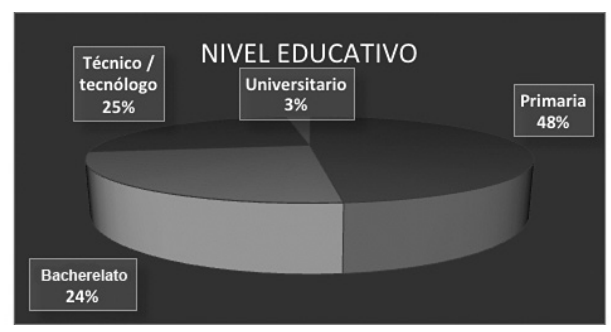

\begin{tabular}{|l|c|}
\hline Nivel Educativo & N \\
\hline Primaria & 42 \\
\hline Bacherelato & 21 \\
\hline Técnico / tecnólogo & 22 \\
\hline Universitario & 2 \\
\hline
\end{tabular}

\begin{tabular}{|l|c|l|c|}
\hline \multicolumn{2}{|l|}{ Servicios de alcantarillado } & Bo & 18 \\
\hline si & 48 & Regular & 20 \\
\hline non & 40 & Malo & 10 \\
\hline Servicio de acueducto & Bo & 27 \\
\hline si & 57 & Regular & 15 \\
\hline non & 30 & Malo & 15 \\
\hline Servicio de enerxía eléctrica & Bo & 80 \\
\hline si & 85 & Regular & 4 \\
\hline non & 2 & Malo & 1 \\
\hline Suministro de gas & 57 & Regular & 4 \\
\hline Gas & 32 & Malo & 3 \\
\hline Cilindro & & & 80 \\
\hline
\end{tabular}

Táboa 2: Cobertura de servicios públicos

Ao consultar si se atopan exposto(a) a perigos de tipo ambiental na zona que habita. O 68\% da poboación considera que se atopa exposta a perigos na zona que habita. O 32\% da poboación non manifestou percibir situacións de perigo na zona que habita. En especial manifestaban sen chegar á seguinte pregunta a preocupación na época de choivas polas inundacións.

En canto aos perigos de tipo ambiental considera vostede que se atopa exposta a comunidade encuestada: dos 87 encuestados, 72 persoas consideran que se atopan expostos aos malos cheiros, 59 a enfermidades, 45 a inundacións e 32 a mosquitos. Así mesmo, 18 persoas consideran que a ubicación da zona facilita que se presenten roubos (Figura e Táboa 3).

Figura e Táboa 1: Nivel Educativo 


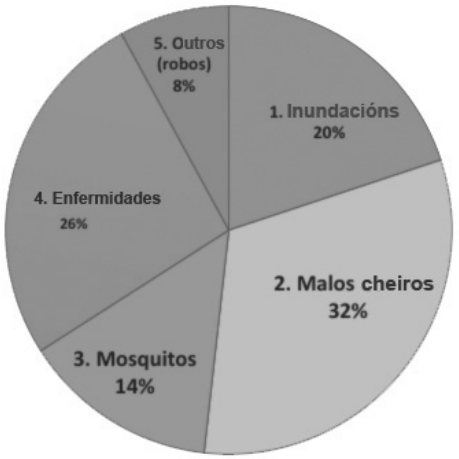

\begin{tabular}{|l|l|}
\hline Posibles Perigos & N \\
\hline 1. Inundacións & 45 \\
\hline 2. Malos Olores & 72 \\
\hline 3. Mosquitos & 32 \\
\hline 4. Enfermidades & 59 \\
\hline 5. Outros (robos) & 18 \\
\hline
\end{tabular}

Figura e Táboa 3: Perigos Ambientais

\section{Concepcións da comunidade}

Considera que coas súas accións vostede causou algunha afectación á cuenca do río Ocoa. Para dar resposta ao segundo obxectivo a concepción do coidado.

Dos 87 encuestados o 55\% ten a concepción que non causou algunha afectación ambiental. Entre tanto, o 45\% ten a concepción que coas súas accións si causou ou causa algunha afectación ambiental á cuenca do río Ocoa, senón máis ben outorgan o deterioro ás accións doutros residentes (Figura 4).

Segundo PINTOU, ALIBERAS e GÓMEZ (1996) "aínda que as ideas espontáneas son construcións persoais e propias de cada

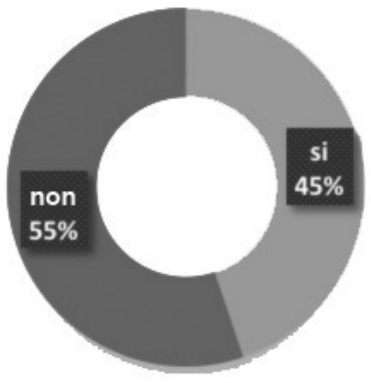

Figura 4: Concepción da afectación do río Ocoa

suxeito, existen moitas máis semellanzas que diferenzas entre elas, o que permitiu identificar algúns esquemas comúns", sendo consecuente co obxectivo da investigación -interpretar as concepcións do coidado do medio ambiente por parte dos habitantes do barrio Ciudad Porfía da cidade de Villavicencio-. Atópanse tópicos comúns, en primeira instancia só $55 \%$ da poboación encuestada considera que afectou a poboación, outros creen que nalgún momento realizaron algunha acción que contribúa á contaminación do río Ocoa

De que forma considera a comunidade encuestada que afectou a cuenca do río Ocoa. Nesta pregunta os encuestados manifestaron varias formas coa cales consideraban que se atopaban afectando a conta do río Ocoa. Sendo a máis común a de escurrir augas residuales á cuenca do río Ocoa dado a que nas zonas baixas se dificultade o acceso ao servizo de alcantarillado. Isto seguido de depositar algunhas veces lixos e invadir róldaa do río Ocoa baixo a necesidade que expresan de ter onde vivir (Figura 5). 


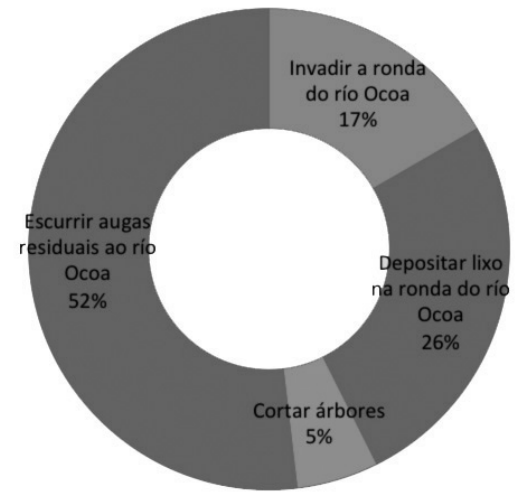

Figura 5: Formas de afectación do río Ocoa

CARRETERO e GARCIA (1984:23) sinalan que "as investigacións sobre os procesos de razoamento humano levadas a cabo nos setenta e principio dos oitenta, revelan a importancia do contido específico sobre o que o individuo razoa". En concordancia con isto a comunidade encuestada manifesta ter unha estreita relación co interese da investigación. Preocúpanse polo ecosistema, pola contaminación onde habitan, interésalles en especial o coidado da auga, para evitar ou diminuír os malos cheiros e ao preguntar cales son as posibles formas de afectación ao río, non se quedan curtos, posto que non dan un só concepto senón varios. Manifestan o interese en apoiar con estratexias para diminuír o lixo, interésanse por coñecer mellor o proceso de reciclaxe; tamén reflexionan sobre a importancia de sementar árbores, para que existan outras especies, para que sirvan de refuxio dos animais, que contribúan como barreira natural e permitan mellorar o clima, diminuír a sensación térmica e como indicou a adulto maior Carmelina SÁNCHEZ: "lograr respirar un aire mellor".

\section{Boas prácticas para o coidado}

Nalgún momento recibiu capacitación de boas prácticas ambientais por parte das autoridades ou organizacións privadas, dando resposta ao terceiro obxectivo boas prácticas para o coidado e a mitigación (Figura 6).

En canto á educación previa do coidado do medio ambiente, ao consultar aos encuestados, atópase que o $89 \%$ indica non recibir nunca capacitaciones de boas prácticas ambientais. E o $11 \%$ indicou si haber ter a oportunidade de asistir a capacitaciones sobre boas prácticas ambientais en especial durante a súa formación escolar. FRAUME (2007:9), cita á educación ambiental como a "acción e efecto de formar e informar á colectividade sobre todo o relacionado coa definición, conservación e restauración dos distintos

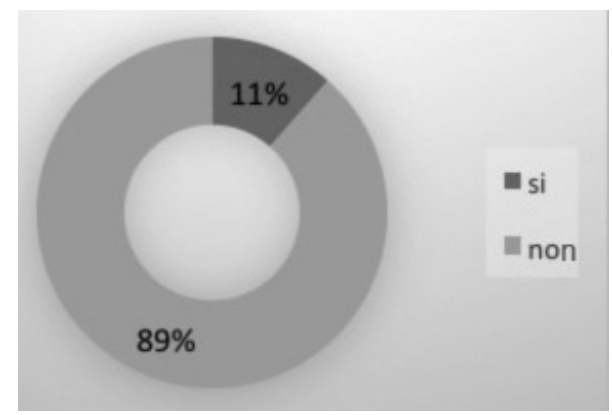

Figura 6: Capacitacións e boas prácticas ambientais 
elementos que compoñen o medio ambiente". Nesta pregunta é importante ter en conta que aínda que é certo só o $11 \%$ da poboación encuestada manifesta ter coñecemento sobre boas prácticas ambientais, a gran diferenza faia o $89 \%$ que manifesta non ter coñecemento, sendo isto asociado tamén ao baixo nivel de escolaridade dos encuestados (só o 48\% tiñan como máximo nivel de estudo algún grado de primaria) o que fai comprensible a relación entre o acceso á educación e o escaso coñecemento.

Cando se suscitan actividades na comunidade para o coidado na ronda do río Ocoa, o 54\% da poboación manifestou a intención de participar ou invitar a alguén do seu núcleo familiar a participar. Pola contra, o 46\% non manifestou interese en participar neste tipo de actividades, algúns indicaban que non contaban con tempo debido ás obrigacións labores (Figura 8).

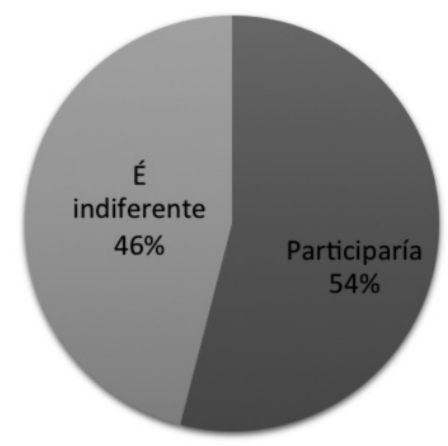

Figura 8: Plantexamento de actividades
Desenvolvemento:

Formulación de estratexias de apoio á comunidade

Para a formulación das estratexias de apoio á comunidade considéranse as que se atopan asociadas ás liñas estratéxicas que promoven os obxectivos de desenvolvemento sostible. En especial o obxectivo 4, educación de calidade, e retomando a definición de LEÓN (2007:596) “a educación é un proceso humano e cultural complexo. Para establecer o seu propósito e a súa definición é necesario considerar a condición e natureza do home e da cultura no seu conxunto, na súa totalidade, para - que cada particularidade ten sentido pola súa vinculación e interdependencia coas demais e co conxunto". En especial atopamos na educación ambiental unha esperanza en concientizar e mellorar as prácticas ambientais, pois esta, segundo NOVO (2009:98), marca "o cambio de mirada que superpón á educación ambiental, desde un contexto máis reflexivo, crítico e constructivista dos seres humanos e a relación coa natureza". Desde este sentir xorde a proposta da investigadora de realizar os obradoiros con nenos/as, novos e adultos maiores, isto grazas ao achegamento inicial que se realizou na recolección da información correspondente ao cuestionario enquisa. Estes talleres chamaranse "ambientando". 


\section{Contido:}

Obradoiro 1. Residuos sólidos e reciclaxe Obradoiro 2. A auga

Obradoiro 3. A saúde e o autocoidado

Obradoiro 4. Perigos naturais do medio ambiente tendo en conta o lugar de residencia.

Convocatoria: invitáronse a 30 nenos/ as e mozos da comunidade, en promedio asistiron 22 nenos/as e novos os cales corresponden ao $73 \%$ da poboación convocada (Fotografías 1 e 2).

Para dar resposta ao obxectivo de interpretar as concepcións do coidado do medio ambiente por parte dos habitantes do barrio Ciudad Porfía da cidade de Villavicencio, nos talleres realizados exploráronse conceptos ambientais previos, nas preferencias desde o cualitativo descóbrense mozos moi inquedos, fascinados polas redes sociais, dinámicos e notouse gran receptividade, interese e espírito de liderado en formación de temas de tipo medio ambiental.

Este é o inicio do que se espera sexa un proxecto constante para o desenvolvemento sostible do sector posto que corresponden; a comunidade en formación propón durante o desenvolvemento dos obradoiros apoiarse nas novas tecnoloxías para o control e seguimento das novidades ambientais da zona e as decisións de goberno.

Desta forma tamén se acada a resposta ao terceiro obxectivo da investigación o cal busca establecer as boas prácticas para o coidado e a mitigación da contaminación da ribeira do río Ocoa. Desde o desenvolvemento destes obradoiros discútese e conclúese que, desde a perspectiva dos mozos, a primeira acción que se debe ter é cambiar as condutas
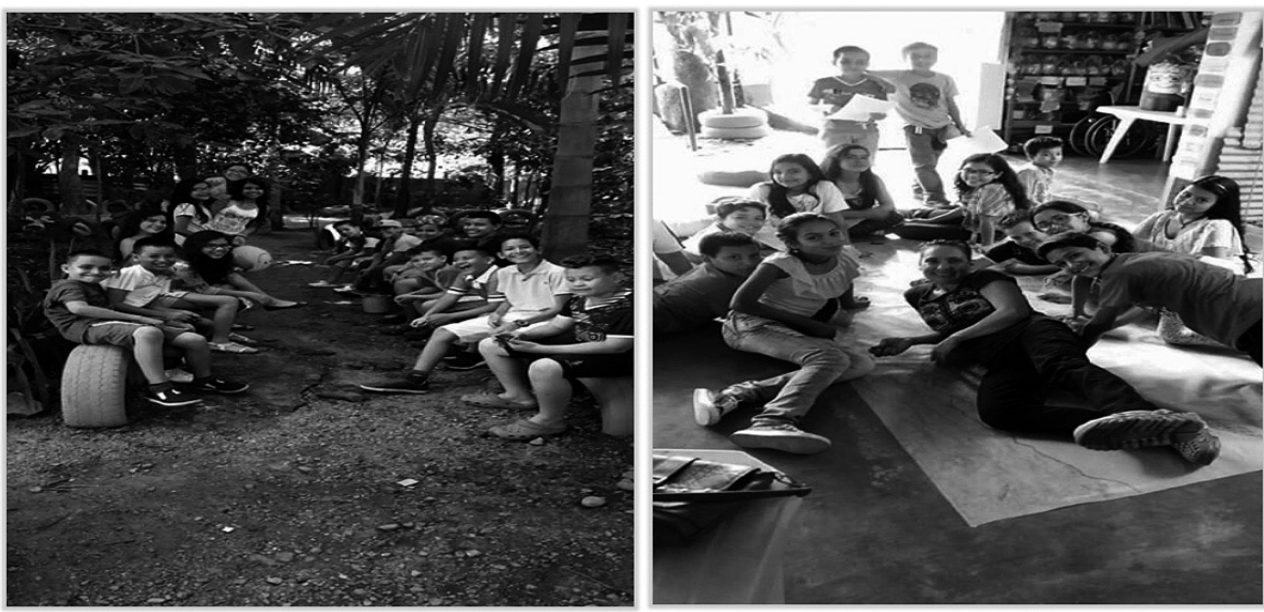

Fotografías 1 e 2: Capacitación dos/as nenos/as e xóvenes 
individuais deles, sendo exemplo nos seus núcleos familiares ou fogares, nos cales empézase a notar que ao mellorar as condutas en temas como a disposición de residuos sólidos, a separación de residuos na fonte e o coidado do medio ambiente. Con estes poden dar paso ás boas prácticas para mitigar a contaminación e propoñer novos espazos de reflexión, espazos que permitan socializar as experiencias persoais e familiares deles, para comprender e a longo prazo lograr grandes avances ao mitigar a contaminación do río Ocoa.

A experiencia de traballo con estes adultos maiores foi especialmente significativa para esta investigación porque no 100\% destes manifestan un marcado interese e respecto pola natureza. Indican que reciclan conservando o vidro e o plástico e que lles preocupa que a auga do río Ocoa estea cada vez máis escura e que diminuira a vida das especies no sector. Con todo, non perden a esperanza. Algúns deles din

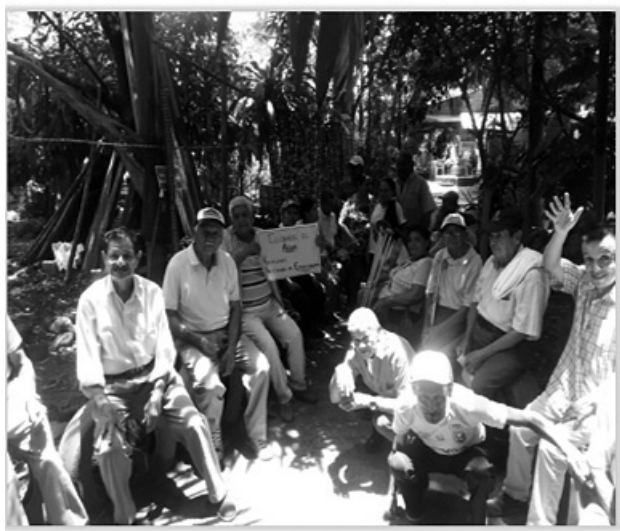

ver lontras na zona. No desenvolvemento dos obradoiros ambientando, contouse coa asistencia de 47 persoas das 60 convocadas, o que corresponde ao $73.3 \%$ da poboación invitada. Nestas capacitacións promovíase a sensibilización e boas prácticas ambientais para mitigar a contaminación da marxe do rio Ocoa por parte dos habitantes do sector. Os participantes asumían o compromiso de ser multiplicadores desde a súa contorna e se resaltaba o valor que terá para a sociedade seguir como vixías ante a necesidade de resgardar o ecosistema natural e comprender a natureza como un todo que retribúe con benestar e calidade de vida (Fotos 3 e 4).

\section{Discusión}

Segundo CALIXTO e HERRERA (2010: 228), a educación ambiental é un campo emerxente de construción de

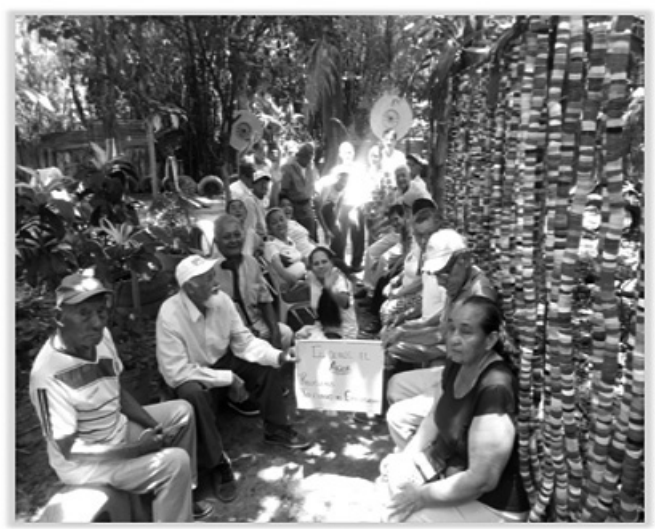

Fotografías 3 e 4: Capacitación cos adultos maiores 
novas propostas, demanda doutros campos de estudo, información para comprender a orixe dos comportamentos ambientais desfavorables cara ao medio ambiente. Asúmese que a forma en que a persoa percibe e constrúe os problemas ambientais, non se sustenta, necesariamente, nunha forma neutral de contemplar o mundo; estas percepcións e os sesgos que as levan a privilexiar certos problemas por sobre outros con distintos grados de importancia, están influídas por intereses e relacións de poder. Neste artigo analízanse as implicaciones que ten a investigación sobre percepcións ambientais para a educación ambiental.

En canto á comunidade aledaña ao río Ocoa, sector barrio Cidade Porfía, nesta identifícase unha zona con servizos públicos, pero cunha notoria dificultade coa rede de alcantarillado. Así como, un nivel de educación escolar en promedio do 48\% con educación primaria. No correspondente ao sinalado á luz da pregunta de investigación Cales son as concepcións e prácticas do coidado para a mitigación da contaminación da marxe dereita do río Ocoa, por parte dos habitantes do barrio Cidade Porfía na cidade de Villavicencio? A comunidade encuestada presenta un 89\% de descoñecemento sobre o coidado do medio ambiente. Con todo, manifesta nun $55 \%$ interese en participar ou invitar a un membro da súa familia en talleres ou proxectos que promuevan o coidado do medio ambiente, as boas prácticas que permitan o coidado da cuenca hidrográfica para a mitigación da contaminación do río Ocoa sector barrio Cidade Porfía. Da mesma forma o $45 \%$ da poboación que non manifesta ter responsabilidade na contaminación ambiental da zona, é consente que outros residentes realizan accións que afectan o ecosistema e a ribeira do río Ocoa.

É imperante atender e centrar os esforzos da comunidade e do goberno local, en xerar maior atención á cuenca hidrográfica do Río Ocoa, como se indicou antes, a auga perdeu a súa calidade, isto clasifícase como "grave" dado que se evidencia na comunidade o aumento do nivel de contaminación odorífera e deterioro da paisaxe natural. A comunidade require avanzar en temas de xestión ambiental, iniciar con educación ambiental, como elemento de servizo comunitario que permita xerar entre a poboación coñecemento da contorna e empoderamiento do contexto. Isto na procura das concepcións de creación de conciencia ambiental, mediante a utilización de ferramentas educativas que permitan mitigar o impacto ambiental xerado pola comunidade aledaña á zona de afectación. Logrando así aportar ás políticas e boas prácticas de desenvolvemento social e medio ambiental da comunidade, máis aínda, cando a través da fundamentación teórica hase evidenciado que os resultados da investigación están relacionados desde a concepción da contaminación ata o coidado para considerar ou alcanzar 
estratexias comunitarias que permitan diminuír a clasificación de contaminación como "grave" e a longo prazo, diminuír a contaminación do Río Ocoa por parte dos habitantes do barrio Cidade Porfía.

Aínda que é certo, o goberno nacional, departamental ou municipal, formula estratexias desde o papel, para o manexo ambiental das augas, a realidade é que o río Ocoa non ha ter ningún efecto en beneficio da fonte hídrica, pois visualmente cada vez atópase máis deteriorada a cuenca hidrográfica. Ao investigar, non se atopa documentadas estratexias de educación ambiental; para a construción de instrumentos de xestión ambiental, que poidan contribuír a mitigar a contaminación causada no área de incidencia do río Ocoa, sector do barrio Cidade Porfía; isto desde o concepto e a posición persoal que desde a xestión da comunidade para a protección dos recursos naturais; pode permitir que os habitantes do sector da cuenca hidrográfica, consideren as variables medio ambientais da contorna e se empoderen dos recursos de xestión cidadáns; que lle permitan participar e gestionar nas institucións públicas e privadas. Para a alcanzar plans de acción a favor da recuperación das condicións naturais da cuenca hidrográfica do río Ocoa, ou a regularización ou disminución do impacto ambiental. A educación ambiental débese impulsar porque é de gran relevancia, promover entre habitantes condutas ou accións que permitan empoderar ao ser humano da responsabilidade social e ambiental en todos os escenarios nos que está inmerso. Facilitando a posibilidade de organizarse como comunidade ou colegiados, motivando o uso equilibrado dos recursos naturais que á súa vez garantan condicións de vida dignas e saudables.

Durante o desenvolvemento dos talleres ambientando, contouse cunha participación do $83 \%$ da poboación encuestada, logrando ter acollida en nenos (as), novos e adultos maiores; colocando a primeira semente que permita ser a apertura a novos espazos de promoción, capacitación e colectivos que aproben propoñer mellores estratexias e prácticas ambientais que logren, a longo prazo, mellorar e mitigar a contaminación na cal está exposto o río Ocoa, sector barrio Cidade Porfía.

É conveniente continuar desenvolvendo actividades ou capacitaciones que permitan continuar coa construción un concepto claro da importancia da dimensión ambiental para a comunidade. Que permitan mellorar e fortalecer as boas prácticas para o coidado e a mitigación da contaminación da cuenca hidrográfica do rio Ocoa sector do barrio Cidade Porfía.

Esta investigación deixou como primeiro aporte, a elaboración da caracterización socio-ambiental da poboación encuestada sector marxe dereita río Ocoa, analizado segundo o cuestionario de preguntas. 
En segunda instancia aporta os tópicos sobre as concepcións de contaminación ambiental que ten os residentes, atopando unha comunidade case dividida entre o crer que é axente que contamina ou só un espectador; con todo, neste apartado lógranse identificar os aspectos fundamentais que a comunidade concibe como contaminantes. De igual forma, lógrase identificar que a comunidade manifesta un interese por mellorar as prácticas que desenvolven para lograr o coidado do auga. Como terceiro aporte deixa na comunidade a realización de catro talleres coa pretensión de orientar á comunidade participantes con conceptos de educación ambiental, autocuidado, perigos ambientais, saúde, reciclaje, recolección, coidado do auga e do aire; buscando iniciar un recoñecemento dun mellor estilo e prácticas de vida a diario para a longo prazo ser exemplo doutros e propulsor da disminución da mitigación da contaminación do río Ocoa.

\section{Conclusións}

$\mathrm{Na}$ elaboración da caracterización da poboaciónaledaña do río Ocoa sectorvarreu Cidade Porfía, atopouse que o máximo nivel de estudo atopado corresponde a primaria cun $48 \%$. Doutra parte o $62 \%$ da poboación encuestada ten unha ocupación laboral; en canto á cobertura aos servizos públicos vitais a zona ten acceso a estes. Con todo, o acceso ao servizo de acueducto se dificulta porque é unha rede creada pola cidadanía fai máis de 20 anos, con condicións deficientes.

Ao Interpretar as concepcións que ten a comunidade encuestada sobre o coidado do medio ambiente dos habitantes do barrio Cidade Porfía da cidade de Villavicencio. Conclúese desde o cuantitativo que só - $45 \%$ dos encuestados consideraban coas súas accións provocar afectación ambiental. Con todo, grazas á conversación en cada fogar encuestado desde o cuantitativo atópase un interese especial en que os membros novos e maiores do fogar vincúlense a talleres ou capacitaciones que permitan coñecer, controlar ou coidar o medio ambiente en especial polo sector de residencia.

Durante o desenvolvemento da aplicación das estratexias das capacitaciones que se realizaron tipo taller segundo conversación cos asistentes, espertouse gran interese por coñecer máis sobre as boas practicas do coidado do medio ambiente, en especial para lograr diminuír a contaminación do rio Ocoa. Así mesmo, manifestouse o interese de promover desde a comunidade comunicados como á alcaldía ou a empresa de acueducto ou alcantarillado que permitan mellorar a rede deste servizo e con isto diminuír o depósito de augas residuales ao rio Ocoa sector barrio Cidade Porfía.

O medio ambiente é un ben común, é un 
espazo que debe integrar a todos e non únicamente desde o inicio dun plan de capacitaciones ou de talleres, máis ben corresponde a toda a cidadanía do sector mellorar as condutas diarias, promoviendo máis a separación na fonte, o reciclaje, a limpeza nas rúas; para así alcanzar mellor concepción do estado de saúde.

O traballo con nenos (as), novos e adultos maiores é esperanzador entendendo que son as persoas que permanecen máis tempo no fogar e son quen coas súas boas prácticas serven como inspiración para a longo prazo controlar e diminuír o índice de contaminación do rio Ocoa sector barrio Cidade Porfía.

Nesta investigación fíxose notoria a ausencia das organizacións do Estado como a Corporación Autónoma Cormacarena, a Secretaria do Medio Ambiente, é pertinente que estas se presenten na zona e promoviendo plans, proxectos e programas do coidado do medio ambiente.

Recoméndase que a Alcaldía da Cidade de Villavicencio apóiese ao acueducto comunitario do barrio Cidade Porfía, para que o sector encuestado mellore a rede a acceso ao acueducto e a través desta, mellorar e diminuír as augas residuales que están desembocando no río Ocoa.

É conveniente continuar desenvolvendo actividades como capacitaciones que permitan continuar coa construción un concepto claro da importancia da dimensión ambiental para a comunidade. Que permitan mellorar e fortalecer as boas prácticas para o coidado e con estas centrar á comunidade na mitigación da contaminación da cuenca hidrográfica do rio Ocoa sector do barrio Cidade Porfía. Isto, tendo en conta os achados relacionados neste artigo os cales indican que se debe promover con maior forza o coidado do medio ambiente para mitigar dunha forma máis efectiva a contaminación ambiental en especial a do recurso auga do río Ocoa sector barrio Cidade Porfía.

\section{Recoñecemento}

Este artigo é produto da investigación "Concepcións e prácticas do coidado para a mitigación da contaminación do río Ocoa por parte dos habitantes do barrio Ciudad Porfía da cidade de Villavicencio", como traballo de grao para optar ao título de Master en Desenvolvemento Sostible e Medio Ambiente da Universidade de Manizales.

\section{Referencias bibliográficas}

ÁLVAREZ e VEGA (2009). Actitudes ambientales y conductas sostenibles. Implicaciones para la Educación Ambiental, Revista de Psico didacta, Vol. 14, páxs. 245-260.

BAHAMÓN (2016). Análisis de las comprensiones que hacen las comunidades aledañas la Chorrera sobre las afectaciones generadas por los vertimentos de aguas residuales urbanas del Municipio de ISNOS-Departamento de Huila. Manizales: Universidad de Manizales.

BARRERA (2014). Determinación del nivel de conocimiento ambiental de los estudiantes de Básica Secundaria y Media en las instituciones educativas del Municipio de Maniza- 
les. Manizales: Universidad de Manizales.

BENAVIDES (2015). La educación ambiental: estudio de caso, Ciudadela Educativa Cuyabra Armenia Quindío. Manizales: Universidad de Manizales.

BOFF, L. (1995). Ecología: el grito de la Tierra, grito de los pobres. Madrid: Trotta.

CALIXTO e HERRERA (2010). Estudio sobre las percepciones y la Educación Ambiental. Toluca: Universidad Autónoma del Estado de México.

CASTRO, RUBIO e RODRíGUEZ (2013). Análisis y perspectivas de las coberturas de acueducto y alcantarillado en el Departamento del Meta, páxs. 122-128. Villavicencio: Universidad de los Llanos.

CESLA (2018). Indicador de gestión para América Latina CESLA-2018. Madrid: Universidad Autónoma de Madrid.

FUNDACIÓN HORIZONTE VERDE. (2011) Fortalecimiento educativo ambiental de niños y jóvenes de Ciudad Porfía para el mejoramiento de su calidad de vida. Villavicencio: Colegio Las Palmas.

GIRALDO e ZULUAGA (2012). Imaginarios sobre la dimensión ambiental en las perspectivas ética, social y tecnológica de la Institución Educativa San Pedro Claver. Manizales: Universidad de Manizales.

HERNÁNDEZ (1979) Onésimo. Elementos de probabilidad y estadística. México D.F. Fondo de Cultura Económica.

LEÓN (2007). Qué es la educación. Red de Revistas Científicas de América Latina, el Caribe, España y Portugal, páxs. 595-604.

MARTÍNEZ (2015). Educación Ambiental para la construcción de una cultura ambiental desde la primera infancia, con niños y niñas del grado primero de Primaria. Manizales: Universidad de Manizales.

MONJE (2011). Metodología de la investigación cuantitativa y cualitativa. Guía didáctica. Neiva: Universidad Sur Colombiana.

MUÑOZ e de PEDRO (2005) Educar para la resiliencia. Un cambio de mirada en la prevención de situaciones de riesgo social. Revista Complutense de Educación, Vol.16, páxs.107-124

NACIONES UNIDAS (2015). Convención marco sobre el Cambio Climático. Acuerdo de Paris. Paris: ONU.

NACIONES UNIDAS (2016). Agenda 2030 y los objetivos de desarrollo sostenible. Una oportunidad para América Latina y el Caribe. Santiago de Chile: CEPAL.
NOVO, M. (2006). El desarrollo sostenible. Su dimensión ambiental y educativa. Santiago de Chile: Universidad de los Lagos.

NOVO, M. (2009). La educación ambiental, una genuina educación para el desarrollo sostenible. Madrid: Universidad Nacional de Educación a Distancia (UNED).

OSPINA, G. (2015). Sentidos y practicas de 10 ambiental en la comunidad de la Institución Educativa Hogar Nazareth Dosquebradas (Risaralda). Manizales: Universidad de Manizales.

Papa Francisco (2013). Laudato Si. Sobre el cuidado de la casa en común. El Vaticano: Miserando Atque Eligendo.

RODRÍGUEZ (2018). Evaluación de la vulnerabilidad social y riesgo ambiental de los habitantes del barrio Las Gaviotas del Municipio de Villavicencio, frente a la amenaza natural que representa la cercanía al Río Ocoa. Villavicencio: Universidad Santo Tomás de Aquino.

SAUVE, L. (2000). Para construir un patrimonio de investigación en educación ambiental, Tópicos en Educación Ambiental, 2 (5), páxs. 51-68.

SEN, A. (2000). Desarrollo y libertad. Buenos Aires: Editorial Planeta.

TAMAYO, M. (1999). La investigación. Santa Fé de Bogotá: ARFO Editores.

TAMAYO, M. (2003) El proceso de la investigación científica. México D.F.: Editorial Limusa.

VALDIVIA, RÚA e RODRíGUEZ (2012). Análisis socio-espacial de la cuenca hidrográfica superficial del Río Quibú. La Habana: Universidad de la Habana.

VASILACHIS (2006.) Las características de la investigación cualitativa. Barcelona: Gedisa.

VASILACHIS (2009) Estrategias de investigación cualitativa. Madrid: Gedisa. 